The Chicago School and Ecology: A reappraisal for the digital era

\title{
Karin Wahl-Jorgensen, Cardiff University
}

\begin{abstract}
This article suggests that the Chicago School's use of ecological metaphors has much to offer scholars interested in the complexities of the contemporary media environment. The article opens by considering how the use of ecological metaphors enabled the Chicago School to build an empirical and progressive approach to the study of human forms of organization. It then traces how the use of ecological metaphors has evolved in subsequent scholarship on media and communications. It examines the interest of media ecology scholars in the environment created by technologies, and discusses how proponents of actor network theory have expanded the view of networked actors to encompass technologies, objects and human agents. The article subsequently traces a more recent proliferation of ecological metaphors as a way of understanding globalized and networked media practices. This approach, in turn, enables the reconfiguration of questions around the relationship between media, democracy and citizenship. The paper ultimately suggests that the use of ecological approaches enables scholars to pay attention to the complexities of networked interactions in communities that are geographically bounded but globally connected. This, in turn, points the continued importance of grounded, nitty-gritty empirical work tracing the variety of communicative practices within particular communities, and the ways in which these practices are shaped by relationships between a variety of actors within and beyond these communities.
\end{abstract}




\section{Introduction}

Central to the Chicago School of Sociology's contribution has been their approach to studying urban life. This article explores their development of ecological metaphors for community life, and traces the ways in which such metaphors have shaped work about communication. This encompasses a loosely organized group of scholars coalescing around the umbrella of "media ecology" to investigate the ways in which technologies constitute environments which shape human experiences. The media ecology approach has been complicated by the emergence of actor network theory, and has been followed by traditions of scholarship that view communicative practices in grounded communities through the lens of ecological metaphors. In particular, the Chicago School's understanding of the community as a networked ecology has gained renewed relevance as scholars seek to come to terms with the complexities of the contemporary digital media environment.

For many communication scholars, the work of the Chicago School is best known through the lens of James W Carey's re-reading. To Carey, the group's work was crucial in articulating a more nuanced view of communication and its role in the constitution of community life than that associated with the received history of mass communication research, marked by a continued preoccupation with media effects (e.g. Carey, 1997). Along those lines, Carey discerned in the Chicago School's work an "expansive view of an actual social process, an intense interest in its phenomenology, and a historical understanding of how the media of communication enter a ceaseless temporal process of change (rather than a static snapshot of having or not having an effect" (Carey, 1997: 33).

What has been less foregrounded are ways in which the approach to understanding the complex interactions and relations shaping community life was crafted through the use of 
ecological metaphors. This is particularly true of the ideas advanced by Robert Ezra Park and other scholars working with and around him, including Ernest Burgess and R. D. McKenzie.

The ecology of community life: Park and his followers ${ }^{\mathrm{i}}$

Park has been seen by many observers as the anchor of the Chicago School of Sociology through its most vital period, and amongst the scholars in the group, he was also the one most closely preoccupied with questions around communication, media and journalism (e.g. Pooley, 2006, pp. 64-66). This article focuses on Park's work because of his affinity with these questions. However, Park's view of the city as equal measures living, breathing organism and social laboratory, and his interest in the role of media within it, were hugely influential to his colleagues and students, but also representative of the world view underpinning the Chicago School more broadly. In his influential essay on "The City" (Park, 1925), which set out an ambitious research program that occupied him and his students for the next generation, Park opened with this spirited mission statement:

The city, from the point of view of this paper, is something more than a congerie of individual men and of social conveniences....something more...than a mere constellation of institutions and administrative devices. The city is, rather, a state of mind, a body of customs and traditions, and of the organized attitude wand sentiments that inhere in these customs and are transmitted with this tradition. The city is not, in other words, merely a physical mechanism and an artificial construction. It is involved in the vital processes of the people who comprise it; it is a product of nature, and particularly of human nature.

As the language of this mission statement suggests, Park and other Chicago sociologists were heavily inspired by organic conceptions of sociology, drawing on the work 
of scholars such as Charles Darwin, Herbert Spencer and Georg Simmel. Their empirical and theoretical project took much inspiration from what was then both a thriving and swiftly developing area of scholarship in the field of ecology, drawing on it to develop a framework for an empirically and progressive systematic approach to the study of human forms of organization (see also Bulmer, 1984; Vasishth \& Sloane, 2002) . In Park’s case, the interest in ecology chimed with his romantic self-understanding, derived from his upbringing in the rural Midwest: He proclaimed his love of "the common things, earth, air - the song of the robin and the great herds of common people, simple and natural as cows" (cited in Matthews, 1977, p. 11). Park valorized "the natural" and his research practice reflected this, as he and other Chicago School figures set out to develop a theory of community based on ecological metaphors. For Park and his colleagues, this was not a matter of abstract theorizing. Rather, it served an urgent and vital set of scholarly and political objectives: They intended to "develop a structural ecology of urban life" (Carey, 1997: 31) to better study processes of cultural struggle, change and continuity that they saw unfolding around them in early- $20^{\text {th }}$ century Chicago.

Ecological metaphors were useful for their project precisely because they enabled a grounded description of such processes, taking into account the complex relationships shaping social change and stability in urban communities. They advanced an understanding of the city beyond seeing it as "a physical mechanism and an artificial construction" and instead analyzing it as a "product of nature, and particularly of human nature" (Park, 1925: 1). Park's article on "Human Ecology" - originally published in the American Journal of Sociology in 1936 - is worth examining in detail in setting out the ecological vision of community implicit in the Chicago School's analysis. Here, Park suggested that "the individual units of the population are involved in a process of competitive cooperation, which has given to their interrelations the character of a natural economy. To such a habitat and its 
inhabitants - whether plant, animal or human - the ecologists have applied the term "community" (Park, 2005: 85). The community, thus conceived, is "(1) territorially organized, (2) more or less completely rooted in the soil it occupies, (3) its individual units living in a relationship of mutual independence that is symbiotic rather than societal, in the sense in which that term applies to human beings" (Park, 2005: 85). The human community is shaped by the interaction of four factors which shape changes, including "(1) population, (2) artifact (technological culture), (3) custom and beliefs (non-material culture) [and] (4) the natural resources that maintain at once the biotic balance and the social equilibrium" (Park, 2005: 90). What is particularly striking about this understanding is its acknowledgement of the complexities of interactions between groups and individuals, the technologies they use and their cultural environment. It suggests that we cannot understand any one of these factors in isolation or as a singular cause of social change, but require a systematic analysis of their concrete relationships. Park's conceptualization here serves as a useful reminder of the importance of geographical place - and the resources and constraints of particular bounded locations - which shaped the work of the Chicago School (see also Vasishth \& Sloane, 2002).

Park and his colleagues were cautious to ensure that the use of ecological metaphors was not taken to equate social processes with natural or biological ones. They stressed that culturally constructed communities have more complicated dynamics because the "cultural superstructure imposes itself as an instrument of direction and control upon the biotic superstructure" (Park, 2005: 90). Nonetheless, they suggested that they provide a useful lens for understanding change - particularly sudden or catastrophic ones, including those brought about by technological innovation (e.g. Park, 2005: 88). This points to one of the ways in which this body of work may inform attempts at coming to terms with radical transformations underpinned, facilitated and shaped by technological change, and highlights an important 
area of affinity between the preoccupations of the Chicago School and contemporary scholarship seeking to make sense of the digital era.

In particular, the use of organic and ecological metaphors enabled the Chicago scholars to understand expansion as "physical growth" and the city as having "metabolism, pulse, a 'heart,' erogenous zones" (Lin and Mele, 2005: 92; see also McKenzie, 1925). The view of the city as an ecology meant an understanding that movements, interactions and relations between groups and individual are complex, but also fraught with danger. At the heart of the Chicago sociologists' preoccupations was a distinctly normative and often moralistic project which was aimed not merely at understanding and describing difference but also at taking an active role in ensuring social cohesion and the upholding of moral values as expressed in Park's (1950) research on race relations and cultural difference, and in R. D. McKenzie's interest in the "vagrant and radical" mores of mobile populations (McKenzie, 1925: 79). However, for subsequent urban sociologists dealing with more decentralized communities, the "closed system" approach associated with the ecological approach, and its limited analysis of issues of class, race, gender and ethnicity in their work has been viewed as a significant limitation (Lin and Mele, 2005: 90). Certainly, to contemporary readers, some of this work and the language surrounding it - such as that on the "mentality of racial hybrids" (Park, 1950: 377-392) would appear dated and guilty of essentializing racial difference. However, such an approach was not out of place in the Progressive Era, characterized by a desire for social reform with a strong normative underpinning, and the belief in the ability of science to deliver it (cf. Peters and Simonson, 2004).

Despite these aspirations, Chicago School sociologists simultaneously saw themselves as pioneering a new and more objective social science. Indeed, the use of ecological metaphors served as a "naturalizing move", an attempt at legitimating the still-emerging discipline of sociology within the realm of established scientific disciplines (Gieryn, 2006: 
11). As Park explained his approach, it "became a logical scheme for a disinterested investigation of the origin and function of social institutions as they everywhere existed" (1922, p. 15). Chicago scholars practiced the sociology of the underdog, the misfits and the marginalized -- what Park (1928) called the "marginal man.” It took from progressives and investigative reporters like Upton Sinclair an interest in uncovering the life of seemingly marginalized groups in the city who nevertheless displayed their own complex forms of social organization, including youth gangs, marijuana users, hoboes, taxi dancers, or immigrant Polish peasants (cf. Gallaher 1995).

Newspapers were seen as central to the project of building communities and improving society within the complex urban ecology. The importance of newspapers can be seen, for example, in the extensive work focused on the immigrant press (e.g. Thomas \& Znaniecki, 1919; Park, 1922). It is also evident in Park's failed Thought News experiment designed as a monthly, subscription-based newspaper based on reporting the findings of sociological research for the betterment of society - or a newspaper reporting on "thought" (Pinter, 2003). The interest and belief in newspapers was representative of a broader sense of communication as the cement of social life. As Park and Burgess wrote in the Introduction to the Science of Sociology:

History has been variously conceived in terms of great events, epoch making personalities, social movements, and cultural changes. From the point of view of sociology social evolution might profitably be studied in its relation to the development and perfection of the means and technique of communication (Park and Burgess, 2004, p. 34).

To Park, Burgess and their colleagues at Chicago, questions about how to improve newspapers and other media were central to this process, as they went about studying how the ethnic groups who shared Chicago sought to make sense of and survive there. They saw 
media and communication as integral to the functioning of society in organic terms, but as necessarily part of a larger set of questions around cultural and social processes (e.g. Park, 1938). ${ }^{\text {ii }}$

The Chicago school's ecological metaphors and media scholarship

The emphasis on understanding the communicative life of communities - particularly urban ones - through ecological metaphors - has significant potential for helping us to understand today's complex media environment. Though they have not always explicitly invoked the Chicago School as an influence, a range of scholars have drawn on ecological metaphors as a resource in analyses of the relationship between individuals, groups, and the technologies that mediate and shape their experiences and interactions.

The continued relevance of the Chicago School's work to those interested in media and communication should also be understood within the broader context of a reappraisal of ecological approaches to the complexities of urban life. This has been particularly in the field of urban studies. Here, new approaches have emerged in critical dialogue with, and building on, key assumptions of the Chicago School (see Abbott, 1999). This is exemplified in the work of the so-called Los Angeles School, which takes inspiration from the empirical project of understanding the complexities of urban life but develops new analytical approaches in the face of the "variety, volume and pace of contemporary change" (Dear, 2002: x). Though distancing themselves from the perceived linear view of evolution embedded in the operationalization of ecological metaphors in the Chicago School (Dear, 2002: ix), proponents of the Los Angeles School nonetheless take inspiration both from the transformative impulse underpinning their research program, and also draw on the 
preoccupation with ecology as a justification for an interest in environmental issues (Davis, 1998; Vasishth \& Sloane, 2002). The preoccupations of the Los Angeles School reflect a continued interest in particular geographically bounded communities, but also signal a shift towards recognizing the increasingly globalized, interconnected and technologically mediated forms of community life.

From media ecology to actor network theory: Tracing the interactions between technologies and individuals

For scholars of media and communication, perhaps the most enduring insight of the Chicago School's ecological model has been the ways in which it has emphasized how social change comes about through Understanding the interactions between technologies and individuals has been a key preoccupation of the loosely formed group of scholars coming together under the umbrella of "media ecology." The term "media ecology" was first introduced by Neil Postman, who described it as "the study of media as environments" (Postman, 1970, p. 161). His description of the field's project is worth quoting at length in setting out its distinctive contribution:

Its intention is to study the interaction between people and their communications technology. More particularly, media ecology looks into the matter of how media of communication affect human perception, understanding, feeling, and value; and how our interaction with media facilitates or impedes our chances of survival. The word ecology implies the study of environments: their structure, content, and impact on people. An environment is, after all, a complex message system which imposes on human beings certain ways of thinking, feeling and behaving. . . In the case of media environments ... the specifications are more often implicit and informal, half 
concealed by our assumption that what we are dealing with is not an environment but merely a machine. Media ecology tries to make these specifications explicit (Postman, 1970, p. 161).

This conception is distinctive in its emphasis on the relationship between individuals and the media, and its insistence on the primacy of technologies in generating the environment which shapes individual experiences (see also Scolari, 2012). This represents a clear departure from the interest in forms of social organization and change in urban communities characterizing the Chicago School. Along those lines, for media ecology scholars, a central belief has been that "human beings sit at the center of a media 'ecosystem' or 'media environment,' and that this ecosystem dramatically affects their perception, their cognition, and thus their behavior" (Anderson, forthcoming). What is crucial for media ecology, therefore, is McLuhan's view of media as an "extension of man" (McLuhan, 1964). By viewing media through this lens, they come to be seen as central agents in the production of meaning - as "things to think with, molders of mind, shapers of thought" (Carey, 1997, p. 39).

Alongside McLuhan's work, other scholars taking an interest in the relationship between media attributes and human behavior have been claimed as the intellectual ancestors and relatives of the media ecology tradition. These include figures such as Harold Innes, Walter Ong, Eric Havelock and Joshua Meyrowitz (Postman, 1970; 2002; see also Strate, 2002; Anderson, forthcoming). What they share is an often historical and critical approach to understanding the media's role in shaping society, but also a concern with complicating accounts of media effects, taking into consideration the specific affordances and qualities of technologies as they develop and interact with humans. Despite this distinctive focus, the media ecology tradition is indebted to the Chicago School's development of the idea of a 
"human ecology," which opened up the analytical lens of understanding technologies as embodied and evolving in and through interactions with people, in turn shaping human behavior (e.g. Heise, 2002). Amongst some media ecology scholars, the preoccupation with the living and breathing city, and the nature of community life within it, remains an important normative point of reference. For example, Joshua Meyrowitz' (1985) central argument in his influential book, No Sense of Place is that the increasing importance of television in our lives has broken down our sense of place. This he means both literally and metaphorically: For Meyrowitz, "place" refers to both distinctions between specific geographical locales and communities, but also to the conventional relationships and hierarchies which have shaped social life. The change in the nature of place as a result of the intervention of technologies particularly television, but also, more recently, the internet, has been a consistent theme in Meyrowitz' work .

In his analysis of the group's deployment of the idea of the media ecosystem, Anderson (forthcoming) refers to their "particularly robust understanding of the relationship between media format and the long-term, society-wide impact of that format," conceived in highly naturalistic terms. Anderson (forthcoming) suggests that they:

...extend the particularly "nature-oriented" aspect of the communications ecosystem metaphor to the point where it encompasses the evolution, growth, decay, and balance between different media types [...] Through their sensory impact (and only in part because of their content) these naturalistic media forms operate directly upon the health of the average citizen-consumer in the electronic age, and they themselves affect each other in a way that can mostly closely be compared to one of those little diagrams of the life surrounding a lake or a pond in a grade-school ecology textbook. This tongue-in-cheek description conveys, first of all, the strong agency given to technologies of mass communication in the work of media ecology scholars. But it also 
suggests that the use of ecological metaphors in their approach - though very different from that of the Chicago School - shares the epistemological and methodological orientation to studying social phenomena through the lens of biological and/or natural processes, understanding technologies as interrelated in their effects (e.g. Heise, 2005), and viewing interactions between individuals and technologies as occurring within a closed and knowable system. Indeed, media ecology scholarship has sometimes been criticized for a reductive, media-centric and deterministic view of the effects of technologies (e.g. Heise, 2005), in part as a result of the use of ecological metaphors which quite literally naturalize claims regarding our interactions with media.

Nonetheless, the interest in the dynamic and networked nature of interactions between technologies and individuals has been taken up and refined by a newer group of scholars whose approach shares some conceptual similarities with the Chicago School's ecological model. In particular, actor network theory (ANT) has been increasingly influential over the past few decades in its insistence on viewing human agents, objects and technologies as actors in networks (e.g. Latour, 1993; 2005). Bruno Latour and other scholars associated with ANT, then, wish to move beyond the primacy frequently afforded to either technology or human activity, and instead "extend the word actor -or actant- to non-human, non individual entities" (Latour, 1996: 2). While Latour draws extensively on vocabularies and examples from the natural world, he wishes to overcome the "previous divide between nature, society and discourse" (e.g. Latour, 1993: 67) and instead uses phrases such as "society-nature" to demonstrate their inextricable connection. To understand the agency and power of agents, ANT proposes a methodological approach premised on examining in detail interactions between these actors, mapping in detail the constitution of networks. Though ANT has had limited influence on scholarship in media and communication studies (Couldry, 2008), it has 
inspired scholars tracing consequences of technologies change, particularly in the context of journalistic practice (e.g. Domingo, 2008; 2015).

\section{Understanding new technologies through ecological approaches}

At the same time, over the past decade or so, a highly diverse group of scholars has once more taken up the idea of a media or news "ecosystem" or "ecology." Scholars using this language retain the emphasis on the close relationship between the use of ecological metaphors and the approach to understanding the place of media technologies in our lives but frequently use ecological language in a much looser fashion, bringing phrases such as "news ecology" (e.g. Cottle, 2000) “news ecosystem” (e.g. Anderson, 2011; 2013) and "hybrid media ecology" (Deuze, 2008; Jenkins and Deuze, 2008) into circulation. That is to say, by and large they do not draw on natural processes to develop the means of examining mediated practices. Rather, ecological metaphors are deployed as a sensitizing concept; a ubiquitous and general shorthand for the complexities of the technological, social and legal environment in which we now communicate. They are united in their belief that in the era of a networked

and highly diverse media landscape ${ }^{\mathrm{iii}}$, we can no longer study individual media organizations, texts and practices in isolation. In approaching media from this vantage point, this emerging body of work departs from the orientation of the media ecology tradition's emphasis on the attributes and effects of particular media and forms of content.

At the same time, it also moves beyond the Chicago School's interests in the community that is "more or less completely rooted in the soil it occupies" (Park, 2006: 85) one which is both centralized and localized. Instead, it examines today's networked and hybrid media ecologies as simultaneously virtual and imagined communities (B. Anderson, 1983). Anderson (forthcoming) has traced the recent diffusion of the phrase, "media ecosystem" using Google N-Grams - a "software tool that provides a "big data" overview of 
prevalence of different phrases in Googles' scanned book corpus." The phrase was first tracked in 2001, and "from then on the use of the phrase nearly doubles every year until 2008 (the last year for which data is available).” In 2001, Henry Jenkins was the first academic to use the phrase, in a piece for Technology Review. In the context of discussing the consequences of media convergence, he suggested that a "medium's content may shift, its audience may change and its social status may rise or fall, but once a medium establishes itself it continues to be part of the media ecosystem. No one medium is going to 'win' the battle for our ears and eyeballs" (Jenkins, 2001, p. 93).

What is interesting about Jenkins' use - which has informed the subsequent adaptation of the phrase - is the idea that in the digital era, we can no longer view individual media in isolation, but must understand that our "media ecosystem" is made up of a variety of dynamic and rapidly changing media forms and genres. Here, then the notion of ecology implies a focus on the forest, rather than the trees - on understanding the whole array of practices in their totality, rather than any one of them on their own. Jenkins, writing here and elsewhere, also stressed that today's media ecosystem cannot be understood solely in terms of particular local environments, but rather has to be understood as a set of interconnected, networked, globalizing practices.

This position is in clear distinction to the approach of the media ecology scholars for whom the individual medium was at the center of attention, and also echoes in the work of others who have taken up ecological metaphors to explore the context of convergence, digital media and the increasingly blurred lines between producers and consumers. Yochai Benkler (2006) is one of the scholars most influential in reviving the idea of media ecology in the digital age. In his book, The wealth of networks, he sought to develop an "institutional ecology of communications" to understand the "social settlement that will emerge around the digital computation and communications revolution", through a "context-dependent, causally 
complex, feedback-ridden, path-dependent process” (e.g. Benkler, 2006). Benkler's interest was primarily in the legal battles over shaping what he also referred to as the communications "environment", with respect to issues such as copyright and ownership of information. Here, Benkler stresses some similarities between processes of "social settlement" and biological processes. However, more than anything, the idea of the ecosystem simply provides a useful metaphor for describing the increasingly variegated media landscape. In particular, Benkler analyzes the networked nature of communications, and what he called "peer-to-peer media"forms of media production outside the remit of legacy media, which have only become increasingly significant since Benkler wrote his book in the mid-naughties. Indeed, it is the emergence of social media and the increasing prominence of citizen journalism and usergenerated content, as well as the proliferation of social media which have made the idea of the media ecosystem so relevant precisely because of its ability to capture both complexity and interconnectedness as defining characteristics of ongoing transformation. The redeployment of ecological metaphors, therefore, could be seen as part of a broader shift in the social sciences towards an increased recognition of the complexities inherent in the context of globalized reflexive modernity - as demonstrated, for example, in the increasing prominence of complexity theory as an explanatory framework (e.g. Urry, 2005).

Nonetheless, and despite the looser understanding of ecological metaphors as a metaphor for the distinctive features of today's media landscape, several scholars drawing on this language have, in fact, taken inspiration from both the specific questions asked by the Chicago scholars and their methodological approach to these questions. For example, Simon Cottle (e.g. 2000) has written about the "news ecology" as a way of theorizing today's interconnected, globalized, diverse and complex communications system. While he first used the phrase in 2000 (a year before Henry Jenkins wrote about the "media ecosystem"), he has since then repeatedly drawing on this language in his writing. Cottle has suggested that his 
use of the phrase "news ecology" was in part inspired by the work of the Chicago School, which he had come across in research on the sociology of race relations and ideas around urban ecology. He then developed the phrase to suggest a distinctive approach for studying media ecology in the "context of increasingly complex/cross-over communication forms, flows and formations across local and the global" (Cottle, personal communication, March 2015).

Cottle's comments represent a shift among scholars deploying ecological metaphors towards recognizing communication as taking part in specific and geographically bounded communities that are nonetheless implicated in globalized networks. What unites these scholars is an interest in the locally situated nature of the knowledge and practices of media, and the resultant need to study a more wide-ranging and dispersed set of practices, groups and organizations. This can be seen as an epistemological and methodological legacy of the Chicago School, even if this kinship is only rarely explicitly acknowledged. Such an approach is, for example, evident in the work of the Metamorphosis Project at the University of Southern California, which seeks to develop an ecology of communication to understand the "transformations of urban community under the forces of globalization, new communication technologies, and population diversity" (Ball-Rokeach, 2001). For this group, an ecological approach means understanding the variety of communication forms and technologies available to communities, ranging from face-to-face communication and new media technologies to geo-ethnic media. As such, this approach is indebted to the Chicago School's interest in the varied communicative practices in a bounded but networked community, and understands ecological metaphors as particularly helpful for theorizing the place of new technologies (see also Wellman et al., 2001). It enables us to understand that communicative practices are glocalized - that they are constituted both by particular local/ecological contexts and communication across distant space (Hampton, 2010). 


\section{News ecosystems}

Such preoccupations have begun to shape work that looks at practices of news production and consumption, in the context of an increasingly challenging economic climate and harrowing technological change. These transformations have meant that conventional questions around the relationship between media organizations, citizens and democracy are now profoundly reconfigured and require new theoretical and methodological tools. One of the scholars who has been most explicitly informed by the work of the Chicago School in developing such tools is Chris W. Anderson, who has made a major contribution to the developing the adaptation of ecological metaphors to better understand the contemporary digital media environment (e.g. Anderson, 2011, 2013, forthcoming). Anderson is specifically interested in the "news ecosystem" which he defines as "the entire ensemble of individuals, organizations, and technologies within in a particular geographic community or around a particular issue, engaged in of journalistic production and, indeed, in journalistic consumption" (Anderson, forthcoming). For Anderson, the interest in the networked locality entails a move beyond traditional practices of studying a few isolated newsrooms of elite legacy media. Instead, he examines a broad range of institutions and actors shaping the Philadelphia news ecosystem; some of them well-established and well-resourced; others fleeting and temporary. Such an approach invites us to consider how the stories we tell travel across different media forms, platforms and genres, means of production and consumptions, groups and individuals. At the same time, Anderson's approach also draws on the insights of ANT in understanding technologies, objects and humans as actors in networks. These preoccupations have translated into the study of how a particular news story - on the wrongful eviction and arrest of a group of Philadelphia activists - travelled through the city's news ecosystem, where it "slowly emerged on the internet, exploded into public view, and 
then faded away, all over the course of just a few days. [...] The primary finding of the Francisville Four study was that, rather than news moving effortlessly and dynamically across digital and physical space (as if gliding through the news ecosystem of its own accord), it was rather "pushed" by a variety of actors, activists, and interested journalistic parties." Anderson's approach is one which enables the recognition of a local news ecosystem - one which is geographically grounded, or "rooted in the soil it occupies" - yet also networked both locally and globally, allowing information to circulate across space and time. Such a method has also taken up by others, as in the Pew Center's study of the news ecosystem of Baltimore (Pew, 2010), which "examined all the outlets that produced local news in Baltimore, Md., for one week, surveyed their output and then did a closer examination of six major narratives during the week" and found that "much of the "news' people receive contains no original reporting.“

These approaches provide us with an answer to the conundrum of the complexities of today's globalized and diverse media landscape, drawing on the insights of the Chicago School's ecology, by suggesting that although many things has changed since Park and his colleagues were studying the city almost a century ago, much remains the same. In particular, it suggests that the stories we care about and need continue to be produced, circulated and consumed in a locally situated manner, and that it is only by studying the nitty-gritty detail of local practices that we can understand the social changes which underpin and shape these stories (see also Ball-Rokeach, 2001). This project is all the more urgent in an environment where legacy media are under persistent threat and transformation, where new media organizations come and go more swiftly than ever before, and where the information that citizens need may be increasingly difficult to come by despite the proliferation of channels of information. 


\section{Conclusion}

This article has argued that the Chicago School's use of ecological metaphors - a central underpinning of their work in both normative and methodological terms - has much to offer to scholars interested in the complexities of the contemporary media environment, as it is being dynamically reconfigured by technological, social, political and economic transformations. The article has traced the significance of the notion of ecology in the work of the Chicago School and subsequent traditions which have deployed similar metaphors ranging from media ecology and actor network theory to a more recent proliferation of ecological approaches to globalized and networked media practices.

What is particularly fruitful about analyzing media as part of a broader ecology is the way in which this approach cautions us to pay attention to the complexities of networked interactions not just between individual media forms and technologies and groups and individuals, but also between the many and varied constituent parts of today's media. Furthermore, in recent conceptual developments, scholars have begun to pay attention to the multifarious practices that surround news production, circulation and consumption in particular local and geographically bounded communities. This approach - informed by the methods and normative concerns of the Chicago School - may be a challenging project, but also one which is of vital importance. It calls attention to the fact that new sociological realities require new tools, but also brings us back to the core questions of how practices of news production, circulation and consumption so central to democratic society and citizenship originate and play out in context that are simultaneously local and global; bounded and de-territorialized. 
More than anything, the reappraisal of the Chicago School suggests the continued importance of grounded, nitty-gritty empirical work which pays attention to the variety of communicative practices within particular communities, and the ways in which these practices are shaped by relationships between a variety of actors within and beyond these communities. 
References:

Abbott, A. (1999). Department and discipline. Chicago sociology at one hundred.

Anderson, B. R. (1983) Imagined communities: Reflections on the origin and spread of nationalism. London: Verso.

Anderson, C. W. (2011). Blowing up the newsroom: ethnography in an age of distributed journalism. In D. Domingo and C. Paterson (eds), Making Online News (Vol 2). New York: Peter Lang, 151-160.

Anderson, C. W. (2013). Rebuilding the news: Metropolitan journalism in the digital age. Philadelphia: Temple University.

Anderson, C. W. (forthcoming). The news ecosystem. In C. Anderson, T. Witschge, D. Domingo, and A. Hermida (Eds) Handbook of Digital Journalism Studies. London: Sage. Ball-Rokeach, S.J. (2001). Metamorphosis white paper series: White Paper 1, community storytelling, storytelling community: Paths to belonging in diverse Los Angeles residential areas. Communication Technology and Community Program, Annenberg School for Communication, University of Southern California.

Benkler, Y. (2006). The wealth of networks. New Haven: Yale University Press. URL (accessed March 2015): http://www.benkler.org/wealth_of_networks http://www.benkler.org/wealth_of_networks

Bulmer, M. (1986). The Chicago school of sociology: Institutionalization, diversity, and the rise of sociological research. University of Chicago Press.

Carey, J. W. (1997). The Chicago School and mass communication research. In E. S. Munson \& C. A. Warren, C. A. (Eds.), James Carey: A critical reader (pp. 14-33). Minneapolis, MN: University of Minnesota Press. 
Carey, J. W. (1997). The roots of modern media analysis. In E. S. Munson \& C. A. Warren, C. A. (Eds.), James Carey: A critical reader (pp. 34-59). Minneapolis, MN: University of Minnesota Press.

Cottle, S. (2000). Rethinking news access. Journalism Studies, 1(3), 427-448.

Couldry, N. (2008). Actor network theory and media: do they connect and on what terms? In A.Hepp, F. Krotz, S. Moores and C. Winter (eds.), Connectivity,networks and flows: conceptualizing contemporary communications (pp. 93110). Cresskill, NJ, USA: Hampton Press, Inc., 2008

Davis, M. (1998). Ecology of Fear: Los Angeles and the Imagination of Disaster. New York: Random House.

Dear, M. (Ed.) (2002). From Chicago to LA: Making sense of urban theory. Thousand Oaks, CA: Sage.

Deuze, M. (2008). The changing context of news work: Liquid journalism for a monitorial citizenry. International Journal of Communication, 2, 18.

Domingo, D. (2008). Interactivity in the daily routines of online newsrooms: Dealing with an uncomfortable myth. Journal of Computer-Mediated Communication, 13(3), 680704.

Domingo, D. (2015). Research that empowers responsibility: Reconciling human agency with materiality. Journalism, 16(1), 69-73.

Galliher, J. F. (1995). Chicago's two worlds of deviance research: Whose side are they on? In Fine, G. A. (Ed.) A Second Chicago School? The development of a Postwar American sociology (pp. 164-187). Chicago: University of Chicago Press. 
Gieryn, T. F. (2006). City as Truth-Spot Laboratories and Field-Sites in Urban Studies. Social Studies of Science, 36(1), 5-38.

Hampton, K. N. (2010). Internet use and the concentration of disadvantage: Glocalization and the urban underclass. American Behavioral Scientist, 53(8) 1111-1132.

Heise, U. (2002). Unnatural ecologies: The metaphor of the environment in media theory. Configurations 10(1), 149-168.

Jenkins, H. (2001). Convergence? I diverge. Technology Review, 104(5), 93.

Jenkins, H., \& Deuze, M. (2008). Convergence culture. Convergence, 14(1), 5-12.

Latour, B. (1993). We have never been modern. London: Prentice Hall.

Latour, B. (1996). On Actor-Network Theory: a few clarifications. Soziale welt, 47, 369-381.

Latour, B. (2005). Reassembling the social: An introduction to actor-network-theory. New York, NY: Oxford University Press.

Lin, J., and Mele, C. (Eds.) (2013). The urban sociology reader $\left(5^{\text {th }}\right.$ ed). London and New York: Routledge.

Matthews, F. H. (1977). Quest for an American sociology: Robert E. Park and the Chicago School. Montreal and London: Mcgill-Queen’s University Press.

Meyrowitz, J. (1985). No sense of place: The impact of electronic media on social behavior. Oxford University Press.

Meyrowitz, J. (2005). The rise of glocality. New senses of place and identity in the global village in K. Nyiri (Ed.) A sense of place: The global and the local in mobile communication (pp. 21-30). Vienna: Passagen. 
Park, R. E. and Burgess, E. W. (1925). The city: Suggestions for investigation of human behavior in the urban environment. Chicago: University of Chicago Press.

Park, R. E. (1922). The immigrant press and its control. New York: Harper \& Brothers.

http://www.archive.org/stream/immigrantpressits00park/immigrantpressits00park_djvu.txt, accessed March 18, 2015.

Park, R. E. (1923). The natural history of the newspaper. American Journal of Sociology, 29(3), 273-289.

Park, R. E. (1925). The city: Suggestions for the investigation of huan behavior in the urban environment. In R. E. Park and E. W. Burgess (Eds.) The City: Suggestions for investigation of human behavior in the urban environment (pp. 1-46). Chicago and London: University of Chicago Press.

Park, R. E. (1928). Human migration and the marginal man. The American Journal of Sociology 33(6), 881-893.

Park, R. E. (1950). Race and culture. Detroit: Free Press.

Park, R. E., \& Burgess, E. (2004). From the Introduction to the Science of Sociology (1921). In J. D. Peters and P. Simonson (Eds.), Mass communication and American social thought: Key texts 1919-1968 (pp. 31-34). Lanham, MD: Rowman \& Littlefield.

Peters, J. D. \& Simonson, P. (Eds.) (2004). Mass communication and American social thought: Key texts 1919-1968. Lanham, MD: Rowman \& Littlefield.

Pew (2010). “How News Happens”, Pew Research Center, 11 January 2010, http://www.journalism.org/analysis_report/how_news_happens, accessed 5 July, 2011. 
Pinter, A. (2003). Thought News: A quest for democratic communication technology. Javnost/The Public 10(2), 93-104.

Pooley, J. (2006). An accident of memory: Edward Shils, Paul Lazarsfeld and the history of American mass communication research. Unpublished dissertation, Columbia University.

Postman, N. (1970). The reformed English curriculum. In A. C. Eurich (Ed.), High school 1980: The shape of the future in American secondary education (pp.160-168). New York: Pitman.

Postman, N. (2000). The humanism of media ecology. Proceedings of the Media Ecology Association 1, 10-16.

Scolari, C. A. (2012). Media ecology: Exploring the metaphor to expand the theory. Communication Theory, 22(2), 204-225.

Smith, D. (1988). The Chicago School: A liberal critique of capitalism. Houndsmills: Macmillan Education.

Strate, L. (2002). Media ecology as a scholarly activity. Proceedings of the Media Ecology Association 3, 1-15.

Thomas, W. I., \& Znaniecki, F. (1919). The Polish peasant in Europe and America: Monograph of an immigrant group (Vol. 3). The University of Chicago Press.

Urry, J. (2005). The complexities of the global. Theory, Culture \& Society, 22(5), 235-254.

Vasishth, A., \& Sloane, D. (2002). Returning to ecology: an ecosystem approach to understanding the city (pp. 343-355). In M. Dear (Ed.), From Chicago to LA: Making sense of urban theory. Thousand Oaks, CA: Sage. 
Wahl-Jorgensen, K (2013). The Chicago School and the pre-history of communication studies. In J. Nerone (Ed.), Media History and the Foundations of Media Studies. Blackwell.

Wellman, B., Haase, A. Q., Witte, J., \& Hampton, K. (2001). Does the Internet increase, decrease, or supplement social capital? Social networks, participation, and community commitment. American behavioral scientist, 45(3), 436-455.

\footnotetext{
i This section draws on material originally published in Wahl-Jorgensen, 2013.

ii This is also evidenced in the Thought News experiment discussed in much detail elsewhere (e.g Carey, 1989; Peters 1989).

iii With apologies for using a metaphor which is partly geographical, partly natural.
} 